\title{
Early Detection and Optimized Management of Thyroid Disease in Pregnancy
}

\author{
Fereidoun Azizi ${ }^{1, *}$ \\ ${ }^{1}$ Endocrine Research Center, Shahid Beheshti University of Medical Sciences, Tehran, IR Iran \\ ${ }^{*}$ Corresponding author: Fereidoun Azizi, Endocrine Research Center, Shahid Beheshti University of Medical Sciences, P. O. Box: 193954763, Tehran, IR Iran. Tel: +98-2122409309, Fax: \\ +98-2122402463, E-mail: azizi@endocrine.ac.ir
}

Received: November 5, 2014; Accepted: November 5, 2014

Keywords:Thyroid Diseases; Pregnancy; Prevention

For early detection and optimized management of thyroid dysfunction before and during pregnancy, we have to look at four levels of prevention: primordial, primary, secondary, and tertiary. There are new insights into this concept, which greatly enhance the health promotion of pregnant women

\section{Primordial and Primary Prevention}

Iodine deficiency can harm both mother and child. During pregnancy, increased need for iodine makes sufficient iodine supply extremely important. According to both the American Thyroid Association (ATA) and the Endocrine Society, the daily iodine intake should be 250 $\mu \mathrm{g}$ of iodine for pregnant women $(1,2)$; therefore, all the women who are planning pregnancy or are pregnant should supplement their diet with a daily oral supplement of $150 \mu \mathrm{g}$ of iodine. In the recently published recommendations of the Spanish Society of Endocrinology and Nutrition, pregnant and lactating women should use iodine supplementation even in iodine sufficient areas (3).

Autoimmunity is another condition that can affect the course of pregnancy. To date, there are no evidencebased methods to prevent autoimmune disease or thyroid autoimmunity. Thyroid disruptors are another potential threat to the health of mother and child. Two very recent studies dealt with the exposure to natural or synthetic chemicals interfering with thyroid hormones; that of Taylor et al. (4) suggests that high-end maternal perchlorate levels in pregnant women with hypothyroidism adversely affect the cognitive development of the offspring. The study of Webster et al. (5) indicates that perfluoroalkyl acids (PFASs) might exacerbate the already high thyroid-stimulating hormone (TSH) and low free T4 levels in TPOAb-positive women during early pregnancy, a critical period for fetal brain development.

\section{Secondary Prevention}

In the field of thyroid disease, secondary prevention typically means screening for early detection of thyroid disease. Considering the alterations in the maternal thyroid economy during pregnancy, trimester-specific reference ranges for TSH have been established. These values vary depending on the local conditions of iodine sufficiency or iodine deficiency; therefore, the ATA guidelines (1) refer to reference values obtained from populations with optimal iodine intake. Local laboratories should adhere to these available values; however, if trimester-specific reference ranges for TSH are not available in the laboratory, the following reference ranges are recommended: first trimester, 0.1 to $2.5 \mathrm{mIU} / \mathrm{L}$; second trimester, 0.2 to 3.0 $\mathrm{mIU} / \mathrm{L}$; and third trimester, 0.3 to $3.0 \mathrm{mIU} / \mathrm{L}$.

The introduction of trimester-specific reference ranges has led to a dramatic increase in women classified as being subclinically hypothyroid. This was nicely shown in the Iranian study of Amouzegar et al. (6). Employing international recommendations and local reference ranges, subclinical hypothyroidism was seen respectively in $24.1 \%$ and $11.3 \%$ of women in the first trimester, $15.3 \%$ and $5.9 \%$ of women in the second trimester, and $16.7 \%$ and $6.4 \%$ of women in the third trimester.

The hallmark of secondary prevention is the application of screening tests; however, not all criteria will be fulfilled by justifying universal screening for thyroid disease in pregnant women. Conflicting data exist over whether early detection and treatment reduces morbidity and mortality and whether the benefit of early detection exceeds the risks and costs. The Lazarus et al. study of (7) over 21000 pregnant women who had received antenatal screening at gestational age of 11 to 14 weeks documented that treatment of maternal hypothyroidism did not result in improved cognitive function in children at the age of three years. Our study came to the same conclusion, in-

Copyright (C) 2015, Research Institute For Endocrine Sciences and Iran Endocrine Society. This is an open-access article distributed under the terms of the Creative Commons Attribution-NonCommercial 4.0 International License (http://creativecommons.org/licenses/by-nc/4.0/) which permits copy and redistribute the material just in noncommercial usages, provided the original work is properly cited. 
dicating that children born either to mothers who were treated for hypothyroidism and had normal TSH during pregnancy or to mothers who had hypothyroidism and inadequate levothyroxine with elevated TSH during pregnancy had similar IQ levels and cognitive performance (8). Nonetheless, there are studies reporting an increasing miscarriage rate in women with positive TPOAb and TSH levels between 2.5 and $5 \mathrm{mIU} / \mathrm{L}$ (9) and a twofold to threefold increased risk of complications such as placental abruption and preterm delivery in pregnant women with subclinical hypothyroidism (10). Concerning management acceptability, another criterion for screening wound be possible financial problems for health systems in many developing countries.

How should we treat pregnant women with subclinical hypothyroidism? In pregnant women with subclinical hypothyroidism and negative TPOAb, although there might be some increased risk for miscarriage, there is not enough evidence to propose levothyroxine treatment or no treatment. These women should be followed closely with monthly TSH measurement to detect overt hypothyroidism. In pregnant women, TPOAb-positivity is associated with significantly increased spontaneous miscarriage, recurrent abortion, and preterm delivery and the possibility of increase in TSH and decrease in free T4 in the second and third trimesters. Therefore, women who are positive for TPOAb and have subclinical hypothyroidism should be treated with levothyroxine.

\section{Tertiary Prevention}

Here, the management goals are proper treatment of thyroid disease, avoiding iatrogenic adverse effects, and preventing neonatal disease. In case of overt hypothyroidism, there is an increased risk for miscarriage, preeclampsia, anemia, fetal growth restriction, placental abruption, perinatal mortality, and neonatal morbidity. As the study of Laurberg et al. (11) demonstrates, screening for early detection and treatment of overt hypothyroidism is beneficial because even severe maternal hypothyroidism, if treated during the first half of pregnancy, does not lead to neurocognitive deficiencies in the child. Women on levothyroxine for treating hypothyroidism who are planning pregnancy should have T4 dose adjusted to TSH $<2.5 \mathrm{mIU} / \mathrm{L}$. Women on levothyroxine for treating hypothyroidism who are newly pregnant should increase levothyroxine dose by $30 \%$ and maternal serum TSH should be monitored every four weeks during the first half of pregnancy $(1,2)$.

In case of thyrotoxicosis during pregnancy, both the disease and the treatment can complicate the course and outcome of pregnancy. Known complications of the disease are miscarriage, preterm delivery, low birth weight of the offspring, and stillbirth. Potential treatment risks are liver failure secondary to propylthiouracil treatment and congenital abnormalities in organ formation, when methimazole is given in the first trimester $(1,12)$. Measurements of TSH receptor antibodies (TRAb) during pregnancy are necessary in women with active hyperthyroidism, with a previous history of RAI (radioactive iodine) treatment, and when a hyperthyroid child has previously been delivered or when thyroidectomy is planned during pregnancy (12). Propylthiouracil is preferred for the treatment of hyperthyroidism in the first trimester. Following the first trimester, switching to methimazole should be considered. Effective and evidencebased strategies for early detection and management of thyroid disease during pregnancy are urgently needed to improve pregnancy outcomes and promote health for both mother and child.

\section{References}

1. Stagnaro-Green A, Abalovich M, Alexander E, Azizi F, Mestman J, Negro R, et al. Guidelines of the American Thyroid Association for the diagnosis and management of thyroid disease during pregnancy and postpartum. Thyroid. 2011;21(10):1081-125.

2. De Groot L, Abalovich M, Alexander EK, Amino N, Barbour L, Cobin $\mathrm{RH}$, et al. Management of thyroid dysfunction during pregnancy and postpartum: an Endocrine Society clinical practice guideline. J Clin Endocrinol Metab. 2012;97(8):2543-65.

3. Donnay S, Arena J, Lucas A, Velasco I, Ares S, Working Group on Disorders Related to Iodine D, et al. Iodine supplementation during pregnancy and lactation. Position statement of the working group on disorders related to iodine deficiency and thyroid dysfunction of the Spanish Society of Endocrinology and Nutrition. Endocrinol Nutr. 2014;61(1):27-34.

4. Taylor PN, Okosieme OE, Murphy R, Hales C, Chiusano E, Maina A, et al. Maternal perchlorate levels in women with borderline thy roid function during pregnancy and the cognitive development of their offspring: data from the controlled antenatal thyroid study. J Clin Endocrinol Metab. 2014;99(11):4291-8.

5. Webster GM, Venners SA, Mattman A, Martin JW. Associations between perfluoroalkyl acids (PFASs) and maternal thyroid hormones in early pregnancy: a population-based cohort study. Environ Res. 2014;133:338-47.

6. Amouzegar A, Ainy E, Khazan M, Mehran L, Hedayati M, Azizi F Local versus international recommended TSH references in the assessment of thyroid function during pregnancy. Horm Metab Res. 2014;46(3):206-10.

7. Lazarus JH, Bestwick JP, Channon S, Paradice R, Maina A, Rees R, et al. Antenatal thyroid screening and childhood cognitive function. N Engl J Med. 2012;366(6):493-501.

8. Behrooz HG, Tohidi M, Mehrabi Y, Behrooz EG, Tehranidoost M, Azizi F. Subclinical hypothyroidism in pregnancy: intellectual development of offspring. Thyroid. 2011;21(10):1143-7.

9. Negro R, Formoso G, Mangieri T, Pezzarossa A, Dazzi D, Hassan $H$. Levothyroxine treatment in euthyroid pregnant women with autoimmune thyroid disease: effects on obstetrical complications. J Clin Endocrinol Metab. 2006;91(7):2587-91.

10. Casey BM, Dashe JS, Wells CE, McIntire DD, Byrd W, Leveno KJ, et al. Subclinical hypothyroidism and pregnancy outcomes. Obstet Gynecol. 2005;105(2):239-45.

11. Laurberg P, Andersen SL, Pedersen IB, Andersen S, Carle A. Screening for overt thyroid disease in early pregnancy may be preferable to searching for small aberrations in thyroid function tests. Clin Endocrinol (Oxf). 2013;79(3):297-304.

12. Laurberg P, Nygaard B, Glinoer D, Grussendorf M, Orgiazzi J. Guidelines for TSH-receptor antibody measurements in pregnancy: results of an evidence-based symposium organized by the European Thyroid Association. Eur J Endocrinol. 1998;139(6):584-6. 